\title{
Appendix A. Supplementary data \\ Characterization and effects of binding of food-derived bioactive phycocyanobilin to bovine serum albumin
}

\author{
Simeon Minic a , Dragana Stanic-Vucinic ${ }^{\text {a,b }}$, Mirjana Radomirovic a, Milica \\ Radibratovic $^{\mathrm{c}}$, Milos Milcic ${ }^{\mathrm{d}, \mathrm{e}}$, Milan Nikolic ${ }^{\mathrm{a}, \mathrm{b}}$, Tanja Cirkovic Velickovic ${ }^{\mathrm{a}, \mathrm{f}, \mathrm{g} *}$
}

a Center of Excellence for Molecular Food Sciences, University of Belgrade - Faculty of Chemistry, Belgrade, Serbia

${ }^{\mathbf{b}}$ Department of Biochemistry, University of Belgrade - Faculty of Chemistry, Belgrade, Serbia

c Center for Chemistry - Institute of Chemistry, Technology and Metallurgy, University of Belgrade, Belgrade, Serbia

${ }^{d}$ Department of Inorganic Chemistry, University of Belgrade - Faculty of Chemistry, Belgrade, Serbia

${ }^{\mathbf{e}}$ Center for Computational Chemistry and Bioinformatics, University of Belgrade - Faculty of Chemistry, Belgrade, Serbia

${ }^{\mathrm{f}}$ Ghent University Global Campus, Yeonsu-gu, Incheon, South Korea

${ }^{g}$ Faculty of Bioscience Engineering, Ghent University, Ghent, Belgium

\section{Materials and methods}

\subsection{Fluorescence quenching measurements}

The fluorescence spectra were recorded under thermostated conditions $\left(25^{\circ} \mathrm{C}\right)$, using 5 $\mathrm{nm}$ excitation and $5 \mathrm{~nm}$ emission slit widths. BSA concentration was kept constant $(0.25 \mu \mathrm{M})$ while the PCB concentration varied from $0-0.8 \mu \mathrm{M}$. 
For intrinsic fluorescence experiments, the excitation wavelength was $280 \mathrm{~nm}$, and emission spectra were recorded between 290 and $400 \mathrm{~nm}$. The change in fluorescence emission intensity was measured after exactly $1 \mathrm{~min}$ of adding each aliquot of ligand to the protein solution. Emission of PCB solutions without BSA was subtracted to correct background fluorescence. Fluorescence intensities were corrected for inner filter effects according to the equation (Lakowicz, 2006):

$$
F_{c}=F_{0} 1^{(\text {Aem }+ \text { Aex }) / 2}
$$

Where $F_{c}$ is corrected fluorescence, $F_{0}$ is measured fluorescence, and $A_{e x}$ and $A_{e m}$ are absorbance of PCB at excitation and peak emission wavelength $(340 \mathrm{~nm})$, respectively.

In order to determine the type of quenching, Stern-Volmer's (SV) quenching constant were calculated according to the relationship (Lakowicz, 2006):

$$
\frac{\mathbf{F}_{\mathbf{0}}}{\mathrm{F}}=\mathbf{1}+\boldsymbol{k}_{\mathrm{q}} \tau_{\mathbf{o}}[\mathbf{Q}]=\mathbf{1}+K_{\mathrm{SV}}[\mathbf{Q}](2)
$$

Where $\mathrm{F}_{0}$ and $\mathrm{F}$ are protein fluorescence intensity at $340 \mathrm{~nm}$ without and with $\mathrm{PCB}$, respectively, $k_{\mathrm{q}}$ is the quenching rate constant of the biomolecule, $\tau_{\mathrm{o}}$ is the average lifetime of the biomolecule without quencher $\left(10^{-8} \mathrm{~s}\right),[\mathrm{Q}]$ is the total quencher $(\mathrm{PCB})$ concentration, and $\mathrm{K}_{\mathrm{SV}}$ is the SV quenching constant. The slope of the SV plot is equal to the SV quenching constant.

The association (binding) constant for the BSA-PCB complex was calculated using the equation (Bi, Dinga, Tiana, Songa, Zhoua, Liua, et al., 2004): 


$$
\log \frac{F_{0}-F}{F}=-n \log \frac{1}{[L]-[P] \frac{F_{0}-F}{F_{0}}}+n \log K_{a}
$$

Where $[\mathrm{P}]$ and $[\mathrm{L}]$ are the total concentrations of protein (BSA) and ligand (PCB), respectively, and $K_{a}$ is the binding constant.

Synchronous fluorescence spectra of BSA-PCB complex, with emissions in the range of 290-400 nm, were obtained at two different scanning intervals: $\Delta \lambda 15 \mathrm{~nm}$, tyrosine (Tyr) residues excitation), and $\Delta \lambda 60 \mathrm{~nm}$, tryptophan (Trp) residues excitation, where $\Delta \lambda=\Delta \lambda_{\mathrm{em}}-\Delta \lambda_{\mathrm{ex}}$.

\subsection{Molecular docking}

In our previous studies it was shown that in aqueous solutions at physiological $\mathrm{pH}$ the most stable form of PCB is its mono-anion form (Simeon L. Minic, et al., 2015). The geometry of the ligand was fully optimized using a $6-311++\mathrm{G}(\mathrm{d}, \mathrm{p})$ basis set with the B3LYP densityfunctional theory method. All quantum chemical calculations on PCB were performed with the Gaussian09 program (Frisch, Trucks, Schlegel, Scuseria, Robb, Cheeseman, et al., 2009).

All water molecules, calcium ions and acetate ions were removed from the BSA protein crystal structure downloaded from the Protein Data Bank (http://www.rcsb.org, PDB ID: 3v03). The missing atoms from the crystal structure were built using CHARMM22 force field. To eliminate possible steric clashes between amino-acid side chains, the structure of the protein was optimized for 2000 steps (1000 steps steps with steepest-descent algorithm followed by 1000 steps with Newton-Raphson algorithm) in the CHARMM program (version c35b1) (Brooks et 
al., 1983). AutoDockTools program (version 1.5.6. Sep_17_14) (Sanner, 1999) was used to add polar hydrogens to the protein structure as well as to select ligand rotatable bonds. After optimization, prepared protein and ligand files in the PDBQT format were used as input for molecular docking simulation. For better refinement of orientation of the ligand instead of a single total volume box we used smaller grid box, with the dimensions $28 \times 28 \times 28 \AA$, to accommodate the ligand during the docking run. In order to cover the entire volume of BSA, the grid box was moved to $8 \AA$ apart in each direction with the total of 1089 docking runs produced. The docking studies were carried out with the AutoDockVina program (version 1.1.2) (Trott $\&$ Olson, 2010) with the exhaustiveness parameter set to 100. From each docking run, 9 binding modes with the highest scoring function were retained for further analysis. All figures were constructed using BIOVIA Discovery Studio Visualizer 2016 (Dassault Systèmes BIOVIA, Discovery Studio Modeling Environment, Release 2017, San Diego: Dassault Systèmes, 2016).

\section{References}

Bi, S., Dinga, L., Tiana, Y., Songa, D., Zhoua, X., Liua, X., \& Zhang, H. (2004). Investigation of the interaction between flavonoids and human serum albumin. Journal of Molecular Structure, 703, 37-45.

Brooks, B. R., Bruccoleri, R. E., Olafson, B. D., States, D. J., Swaminathan, S., \& Karplus, M. (1983). CHARMM: A program for macromolecular energy, minimization, and dynamics calculations. Journal of Computational Chemistry, 4(2), 187-217. 
Frisch, M. J., Trucks, G. W., Schlegel, H. B., Scuseria, G. E., Robb, M. A., Cheeseman, J. R., Scalmani, G., Barone, V., Mennucci, B., Petersson, G. A., Nakatsuji, H., Caricato, M., Li, X., Hratchian, H. P., Izmaylov, A. F., Bloino, J., Zheng, G., Sonnenberg, J. L., Hada, M., Ehara, M., Toyota, K., Fukuda, R., Hasegawa, J., Ishida, M., Nakajima, T., Honda, Y., Kitao, O., Nakai, H., Vreven, T., Montgomery Jr., J. A., Peralta, J. E., Ogliaro, F., Bearpark, M. J., Heyd, J., Brothers, E. N., Kudin, K. N., Staroverov, V. N., Kobayashi, R., Normand, J., Raghavachari, K., Rendell, A. P., Burant, J. C., Iyengar, S. S., Tomasi, J., Cossi, M., Rega, N., Millam, N. J., Klene, M., Knox, J. E., Cross, J. B., Bakken, V., Adamo, C., Jaramillo, J., Gomperts, R., Stratmann, R. E., Yazyev, O., Austin, A. J., Cammi, R., Pomelli, C., Ochterski, J. W., Martin, R. L., Morokuma, K., Zakrzewski, V. G., Voth, G. A., Salvador, P., Dannenberg, J. J., Dapprich, S., Daniels, A. D., Farkas, Ö., Foresman, J. B., Ortiz, J. V., Cioslowski, J., \& Fox, D. J. (2009). Gaussian 09. In). Wallingford, CT, USA: Gaussian, Inc.

Lakowicz, J. R. (2006). Principles of Fluorescence Spectroscopy. New York: Springer.

Sanner, M. F. (1999). Python: a programming language for software integration and development. J Mol Graph Model, 17(1), 57-61.

Trott, O., \& Olson, A. J. (2010). AutoDock Vina: improving the speed and accuracy of docking with a new scoring function, efficient optimization, and multithreading. J Comput Chem, $31(2), 455-461$. 


\section{Results}

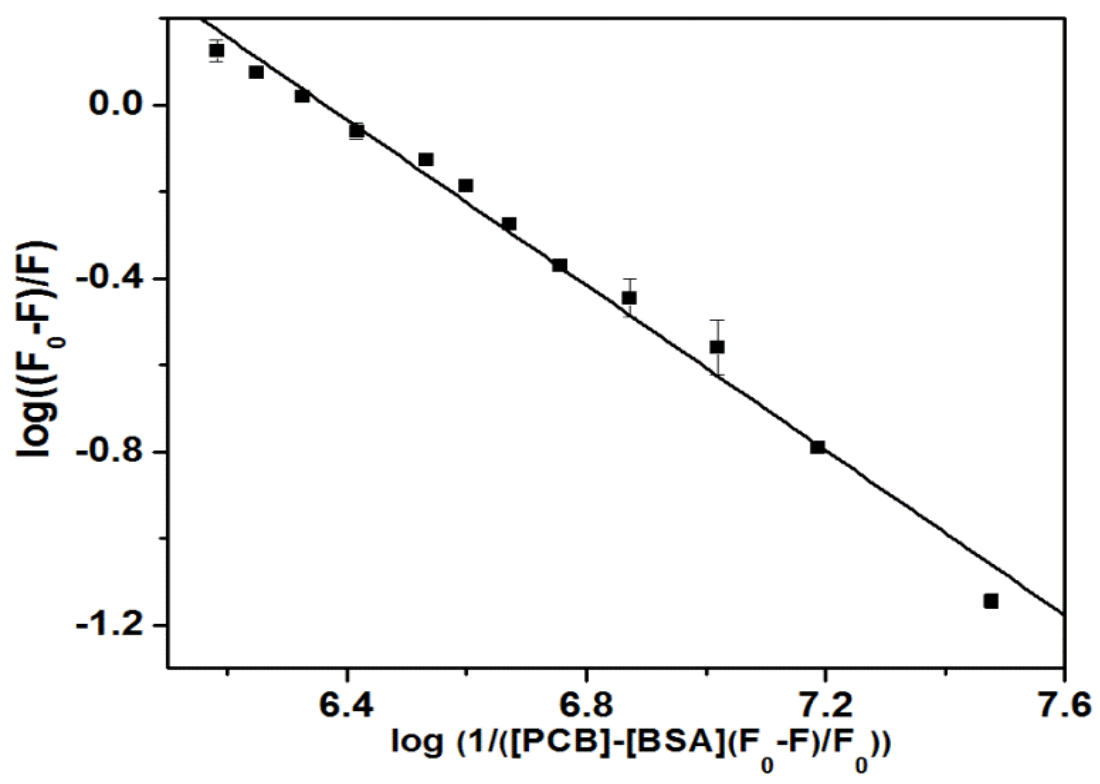

Figure S1. Fluorescence quenching plot for determination of PCB binding constant to BSA. Error bars represent standard deviation $(n=3)$. 

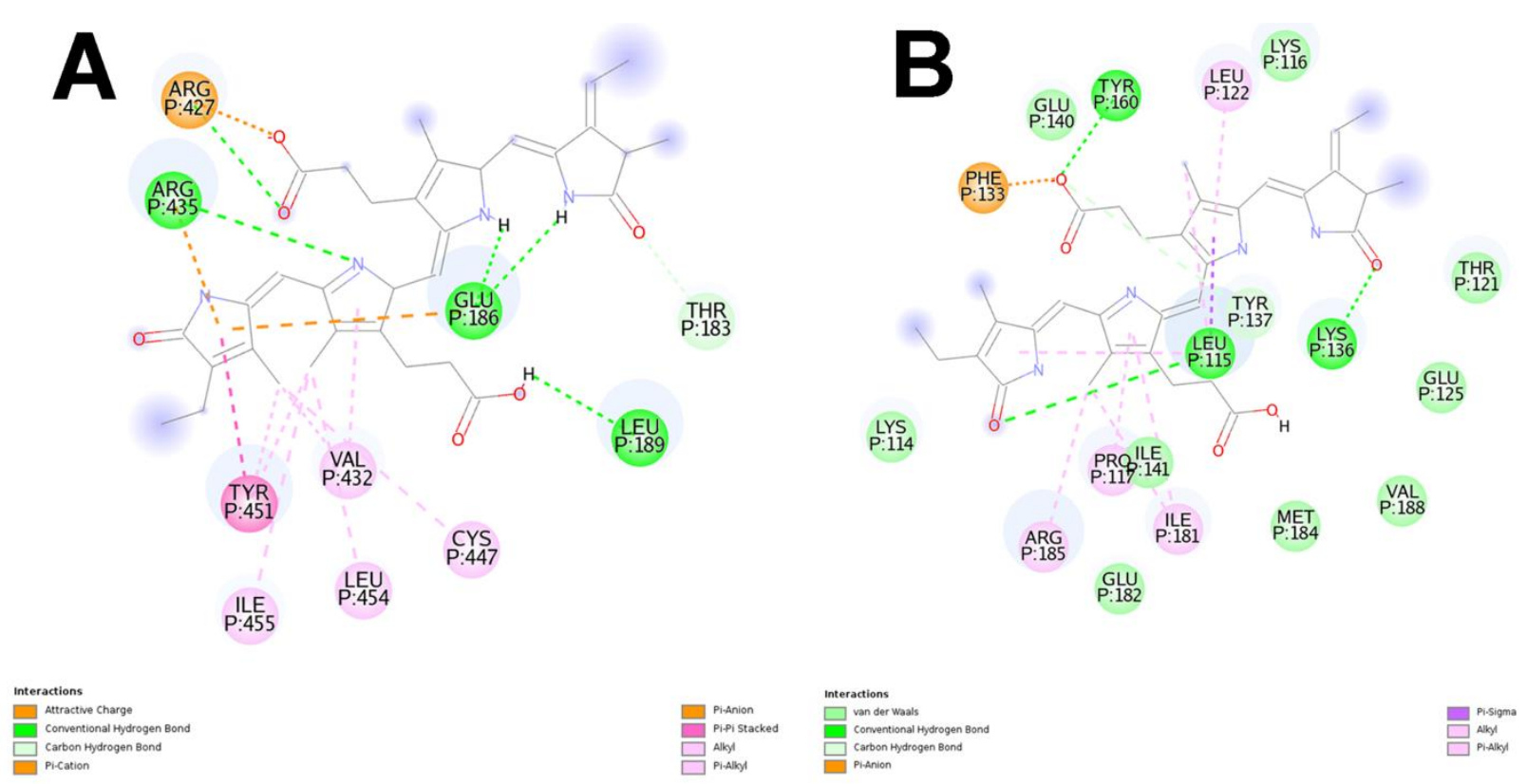

Figure S2. 2D diagram with labeled interactions of docked PCB to BSA (PDB ID: 3V03) at two proposed binding sites: Inter-domain cleft (A) and subdomain IB (B). 


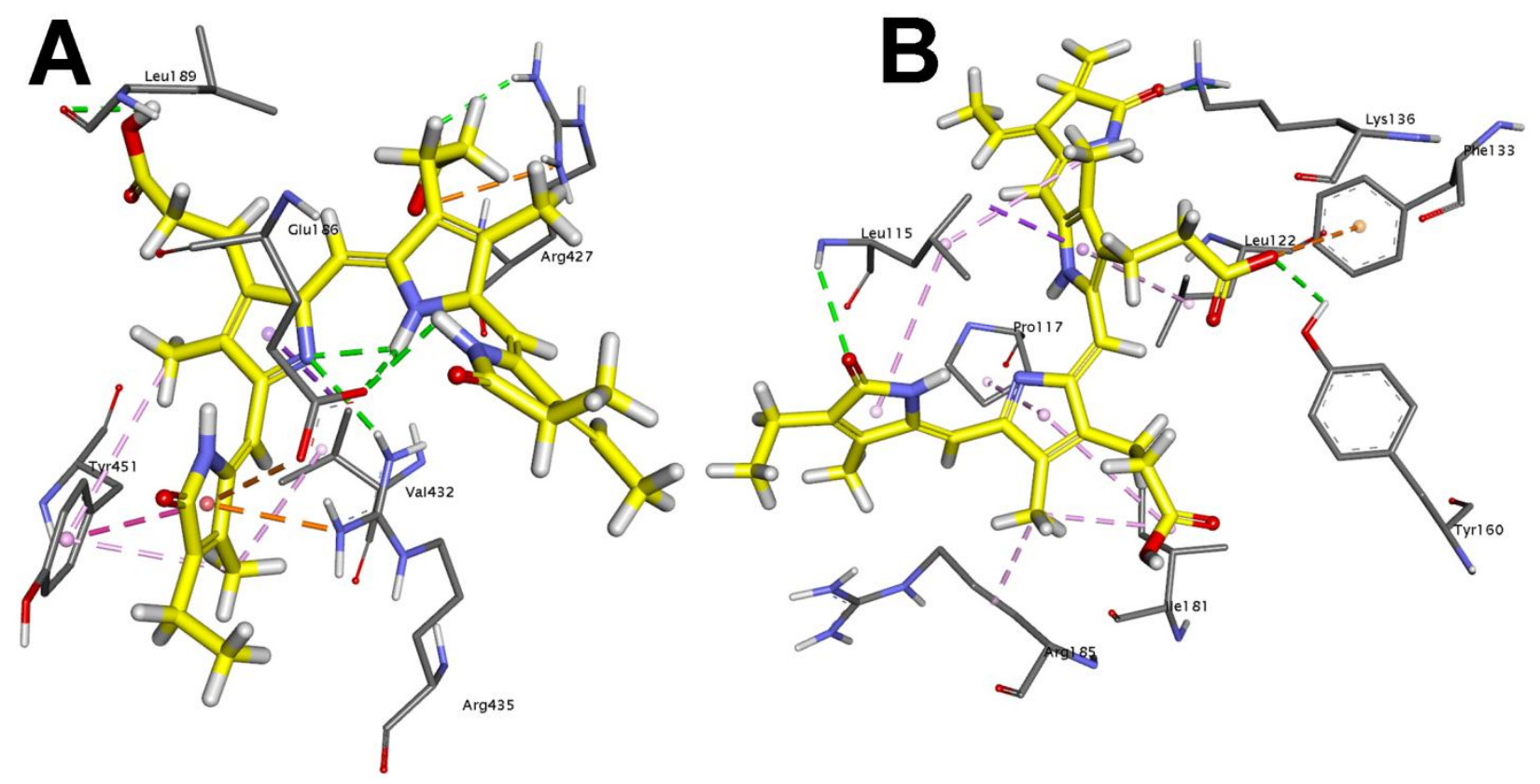

Fig. S3. Proposed main interactions between PCB and BSA (PDB ID: 3V03): at the binding site inter-domain cleft (A) and at sub-domain IB (B). 


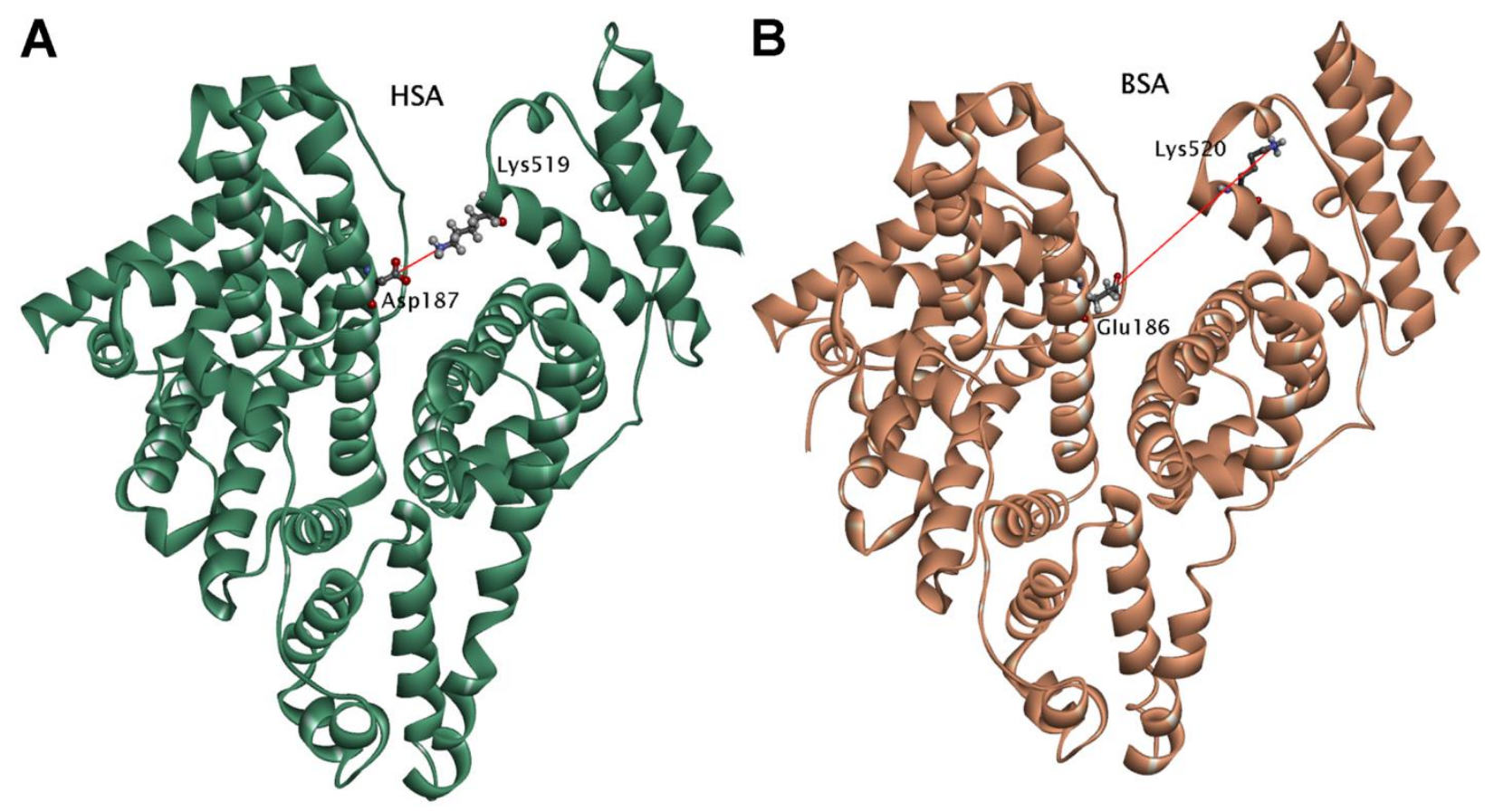

Figure S4. Comparison of distances between Lys-519/520 (domain III) and Asp-187 (domain I) in the inter-domain cleft of (A) human (PDB ID 1BM0) and (B) bovine (PDB ID: 3V03) serum albumin. The distance between domains I and III at the most favorable binding site is shown by the red line: $0.49 \mathrm{~nm}$ between Lys-519 and Asp-187 in HSA, and 1.92 nm between Lys-520 and Asp-187 in BSA. Labeled amino acids are shown as stick models. 